\title{
Impactos ambientais e financeiros da implantação do gerenciamento de resíduos sólidos em um complexo siderúrgico: um estudo de caso
}

\author{
Environmental and financial impacts of the implementation of \\ solid waste management in a steel complex: a case study
}

\begin{abstract}
Carolina Calazans Lopes Leopoldino"* ${ }^{10}$, Djanine Carolina Barbosa ${ }^{2}$ (, Fabrício Molica de Mendonça 2 ,Carlos Eduardo Durange de Carvalho Infante ${ }^{2}$ (อ) Elizete Antunes Teixeira Nogueira ${ }^{2}$ (1)
\end{abstract}

口-

\begin{abstract}
RESUMO
Este trabalho teve por finalidade analisar o processo de implantação do plano de gerenciamento de resíduos sólidos (PGRS) em um complexo siderúrgico, de modo que se identifiquem possíveis ganhos financeiros associados aos ganhos ambientais. Para atender ao objetivo proposto, foi realizada uma pesquisa qualitativa de cunho descritivo e analítico, adotando a pesquisa-ação como estratégia de pesquisa. Os recursos metodológicos usados foram pesquisas bibliográfica, documental e de campo. Os resultados permitiram levantar e classificar os resíduos gerados pelo complexo, para conhecer sua natureza, legislações pertinentes e métodos de tratamento; acompanhar o processo de implantação do novo plano de tratamento de resíduos; e analisar os impactos financeiros associados aos ganhos ambientais. A análise de indicadores mostrou que, até o ano de 2014, as despesas com o gerenciamento de resíduos eram maiores que as receitas. Já em 2015, com a implantação do PGRS, houve aumento de receitas, provenientes de venda de resíduos recicláveis e redução de custos de tratamento de resíduos, mostrando ser possível, com um trabalho coletivo e focado, atender a legislações ambientais e ainda trazer um retorno financeiro para a empresa.
\end{abstract}

Palavras-chave: gerenciamento de resíduos; impactos financeiros; indicadores.

\begin{abstract}
This study aimed to analyze the process of implementation of solid waste management plan (SWMP) in a steel complex, in order to identify possible financial gains associated with environmental gains. To reach the proposed objective, a qualitative, descriptive and analytical research was carried out, adopting action-research as a strategy, The methodological resources used were bibliographical, documentary and field research. Results allow to survey and classify the waste generated by the complex, to know its nature, relevant legislation and treatment methods; to monitor the implementation process of the new waste treatment plan; and to analyze the financial impacts associated with environmental gains. The indicators analysis showed that by 2014 the cost of waste management expenses was greater than revenues. In 2015, with the implementation of the SWMP, there was an increase in revenues from the sale of recyclable waste and a reduction of waste treatment costs, showing that it is possible, with a collective and focused work, to meet environmental legislation and also bring a financial return to the company.
\end{abstract}

Keywords: waste management; financial impacts; indicators.

\section{INTRODUÇÃO}

A preocupação com a gestão dos resíduos sólidos passou a ser propriamente abordada somente em meados do século XX. Até o início dos anos 1970, priorizou-se apenas a disposição final dos resíduos sólidos. A partir de então, com a criação de legislações mais severas, as empresas foram sendo obrigadas a inserir a gestão de resíduos em suas estratégias de negócios.
No âmbito industrial, os resíduos sólidos são gerados tanto nos processos produtivos quanto nas atividades auxiliares, como manutenção, operação de área de utilidades, limpeza, obras e outros serviços (PHILIP JR., 2005; CARVALHO; OLIVEIRA, 2003). Segundo a Norma Brasileira (NBR) no 10004, de 2004, da Associação Brasileira de Normas Técnicas (ABNT, 2004), esses resíduos têm uma classificação específica de acordo com sua periculosidade, sendo divididos 
em classe I - que engloba os resíduos perigosos - e classe II - que engloba os não perigosos.

Os resíduos classe I são os que apresentam alguma periculosidade, como inflamabilidade, corrosividade, reatividade, toxidade e patogenicidade. Já os classe II são divididos em:

- II A, que são os não inertes, ou seja, que podem ter propriedades como biodegradabilidade, combustibilidade ou solubilidade em água;

- $\quad$ II B, que são os inertes.

Os resíduos industriais, de maneira geral, têm sido considerados um dos maiores agressores ao ambiente, porque, neles, estão incluídos produtos químicos (cianureto, pesticidas e solventes), metais (mercúrio, cádmio e chumbo) e solventes químicos, que ameaçam os ciclos naturais dos locais onde são despejados, contaminando rios, mares, ar e solo (RIBEIRO; MORELLI, 2009). Por isso, a gestão ambiental tem buscado intermediar a relação produção sustentável/natureza por meio de políticas de minimização, reciclagem, reutilização, tratamento e disposição final adequada para os seus resíduos (BARTHOLOMEU; CAIXETA-FILHO, 2011; MACHADO et al., 2012).

No Brasil, a Lei no 12.305/2010, que trata da Política Nacional de Resíduos Sólidos (PNRS) (BRASIL, 2010b), e o Decreto $n^{\circ}$ 7.404/2010 (BRASIL, 2010a), que se refere ao gerenciamento desses resíduos no país, associados a outras legislações e normas ambientais vigentes têm dado à gestão de resíduos um papel de destaque nas organizações. Tais legislações buscam ações preventivas ou medidas mitigadoras, voltadas a eliminar ou minimizar os impactos negativos de suas atividades no ambiente ao longo do processo de suprimento e de produção.

Um instrumento eficiente e eficaz para a gestão de resíduos é o chamado plano de gerenciamento de resíduos sólidos (PGRS), que, segundo a PNRS brasileira, deve ser feito pelo setor público, em níveis federal, estadual e municipal, e por empresas públicas ou privadas (BRASIL, 2010b). O PGRS é um documento com valor jurídico que comprova a capacidade de uma empresa de gerir todos os resíduos que eventualmente venha a gerar (TOCCHETTO, 2005). Nele, é definido o conjunto de informações e estratégias integradas de gestão, voltadas a normatizar os procedimentos operacionais de gerenciamento de resíduos sólidos em conformidade com as legislações sanitária e ambiental (ANVISA, 2003).

Segundo Sanches, Mendonça e Feichas (2013), a adoção do gerenciamento de resíduos apenas para atender às legislações sanitária e ambiental, no que se refere à classificação, ao armazenamento, ao transporte e à destinação final dos resíduos, é falha. De acordo com os autores, nesse caso, o controle de resíduos só ocorre no fim do processo, comprometendo a eficiência de gestão. Por exemplo, possíveis contaminações de um resíduo por outro fazem com que volumes consideráveis sejam enviados para aterros sanitários ao invés da reciclagem. Enquanto o aterro aumenta o custo da disposição final, a reciclagem aumenta as possibilidades de ganhos financeiros.
Sendo assim, torna-se necessário fazer com que o PGRS represente, além de um instrumento adequado de gestão ambiental, uma forma de retratar um aumento da competitividade da empresa (FERREIRA; TAMBOURGI, 2009). Por isso, é importante a adoção de um plano capaz tanto de atender às normas e legislações ambientais quanto de proporcionar ganhos operacionais, econômicos e sociais, de modo que esteja ligado ao conceito triple bottom line (PASCHOALIN FILHO et al., 2015).

No que tange ao aspecto econômico, Paschoalin Filho et al. (2015) estudaram a viabilidade econômica da comercialização de matérias-primas provenientes de resíduos de demolição de um prédio em São Paulo. Os ganhos variaram de R $32 . \mathrm{m}^{-3}$ a $\mathrm{R} \$ 138 . \mathrm{m}^{-3}$, o que representa uma interessante alternativa, visto que a opção pelo uso de matérias-primas virgens provocaria um custo três vezes maior para o comprador. Já os ganhos sociais estiveram associados aos aumentos do emprego e da renda.

Autores como Tam et al. (2007), Santin (2009), Hwang e Yeo (2011), Coelho et al. (2011), Yuan (2012), Carneiro (2013), Yates (2013), Sanches, Mendonça e Feichas (2013), Arnosti Jr. e Trinca (2015), Paschoalin Filho et al. (2015) e outros buscaram mostrar as vantagens da realização do PGRS para o bom desempenho ambiental associado aos desempenhos operacional, econômico e social. No geral, tais vantagens estão relacionadas com:

- a redução no consumo de recursos naturais não renováveis;

- a redução de áreas necessárias para aterro, pela minimização de volume de resíduos e pela reciclagem;

- a redução do consumo de energia durante o processo de produção;

- a redução da energia utilizada para extração e transporte dos materiais;

- $\quad$ a redução da poluição;

- a diminuição do transporte dos materiais virgens aos centros consumidores;

- a geração de emprego e renda e melhoria no âmbito social, com uma nova e ampla cadeia produtiva no mercado de trabalho.

Nesse contexto, a adoção de métodos de gerenciamento de resíduos sólidos industriais tem ganhado destaque, porque conseguem, ao mesmo tempo, reduzir o volume de resíduos, atender a legislações específicas e apresentar ganhos econômicos, traduzidos em aumento de receita e/ou redução de custos (RIBEIRO; MORELLI, 2009).

No entanto, quando se fala em gestão de resíduos, o empresário faz associação com custos adicionais, passando despercebidas as oportunidades de ganhos financeiros e ambientais conjuntos, que podem ser obtidos por meio do gerenciamento. Isso faz surgir a seguinte indagação: como o gerenciamento de resíduos, associado aos processos organizacionais, pode contribuir para que a empresa possa obter ganhos ambientais e financeiros sem a necessidade de grandes investimentos em estruturas, equipamentos e consultorias? Para responder a essa questão, é necessário desenvolver estudos de casos específicos, uma 
vez que cada organização é única e apresenta estratégias diferentes de atuação para resolver problemas relacionados aos resíduos.

Assim, este trabalho tem por finalidade analisar o processo de implantação do plano de gerenciamento de resíduos sólidos em um complexo siderúrgico, de modo que se identifiquem possíveis ganhos financeiros associados aos ganhos ambientais obtidos da implantação desse plano. Mais especificamente, este estudo pretendeu:

- levantar e classificar todos os resíduos gerados pelo complexo, para conhecer sua natureza, legislações pertinentes e métodos de tratamento;

- analisar o plano de resíduos adotado pela empresa para gerenciar os resíduos sólidos do complexo;

- analisar os resultados obtidos com a implantação do novo plano de tratamento de resíduos, para poder verificar os ganhos financeiros associados aos ganhos ambientais.

O período de pesquisa compreendeu os anos de 2014 e 2015, já que o complexo siderúrgico em questão implantou o PGRS nesse último ano. Dessa maneira, foi possível verificar como era feita a gestão dos resíduos sólidos antes e depois da implantação do programa.

\section{METODOLOGIA}

Para atender ao objetivo proposto, foi realizada uma pesquisa qualitativa de cunho descritivo e analítico. Esse tipo de pesquisa é o mais indicado para este estudo por permitir o entendimento de impactos sociais e culturais de um fenômeno, visando mais à compreensão do que à quantificação e, ao invés da generalização, tem-se o particular, o individual e o peculiar como foco (TRIVIÑOS, 2009; RAMPAZZO, 2015).

Quanto ao gênero, trata-se de uma pesquisa empírica, que, conforme Demo (2012), é aquela que codifica a face mensurável da realidade social. Como tipo de pesquisa, foi desenvolvido um estudo de caso, pois esse método "investiga um fenômeno contemporâneo em seu contexto do mundo real", buscando entender a complexidade dos fatores sociais, sob uma perspectiva holística (YIN, 2015, p. 32). Com relação à estratégia de pesquisa, foi utilizada a pesquisa-ação, uma vez que, em um trabalho dessa natureza, o pesquisador não é apenas um observador, mas um agente ativo do objeto pesquisado, buscando gerar informações concretas. Esse método de pesquisa deve gerar soluções para as empresas e conhecimento para a academia (THIOLLENT, 2011).

Os recursos metodológicos usados foram pesquisas bibliográfica, documental e de campo. A primeira foi usada para contextualizar o gerenciamento de resíduos sólidos e a sua evolução ao longo dos anos; a segunda, para levantar informações em relatórios, planilhas e outros documentos relacionados ao plano de gerenciamento de resíduos; e a terceira foi realizada por meio da observação in loco e pelo acompanhamento da elaboração e aplicação de um novo plano de gerenciamento de resíduos e pela análise de resultados.
A coleta e a análise de dados foram desenvolvidas em quatro etapas. Na primeira, foram mapeados os resíduos gerados em todas as atividades da empresa no complexo siderúrgico em questão, ressaltando as saídas indesejadas e suas áreas geradoras. Na segunda fase, os resíduos foram classificados conforme o padrão NBR 10004 (ABNT, 2014) e, na terceira, foi desenvolvido, apresentado e implantado o PGRS no complexo siderúrgico, em 2015. Na quarta etapa, a partir da implantação do novo plano e obtenção de resultados, foram levantados os benefícios trazidos com a melhoria do processo de gerenciamento de resíduos sólidos por meio da análise comparativa com o ano anterior.

\section{RESULTADOS E DISCUSSÃO}

\section{Contextualização: os resíduos sólidos no complexo siderúrgico estudado e seu gerenciamento}

O complexo siderúrgico em estudo é uma joint venture que ocupa uma área industrial de 2 milhões $\mathrm{de}^{2}$. Possui capacidade anual de 1 milhão de toneladas de aço bruto e 400 mil toneladas de tubos de aço sem costura. Os tubos produzidos possuem alto valor agregado, atendendo à demanda do setor petrolífero mundial. No ano de 2014, a produção média mensal de aço foi de 27.830 toneladas e, no de 2015, foi de 22.991 toneladas.

A usina integrada dedica-se à fabricação de produtos tubulares petrolíferos oil country tubular goods (OCTG) sem costura, empregados na perfuração e no revestimento de poços (casing) e tubos para condução de petróleo e gás. Os tubos em aços carbono e baixa liga são altamente resistentes às diversas condições de temperatura e pressão.

Nesse complexo, a geração de resíduos sólidos acontece em todas as etapas de produção, manutenção e também em atividades administrativas. O volume de resíduos médio mensal é igual a $1.324 .759 \mathrm{~kg}$, divididos em dois grupos: o 1, relacionado aos resíduos do tipo I ou perigosos, representa $2 \%(32.280 \mathrm{~kg})$ do volume de resíduos-(Tabela 1$)$; o 2, formado pelos resíduos dos tipos II A (não inerte) e II B (inerte), representa $98 \%(1.292 .480 \mathrm{~kg})$ do volume gerado (Tabela 2$)$ e é destinado corretamente, conforme determina a legislação específica.

\section{Gestão de resíduos sólidos antes do plano de gerenciamento de resíduos sólidos}

Até o ano de 2014, o modelo de gerenciamento de resíduos sólidos dentro do complexo era realizado de forma bem simples. O modelo estava voltado para o atendimento a legislações vigentes e o controle dos resíduos era feito apenas no fim do processo, o que, segundo Sanches, Mendonça e Feichas (2013), compromete a eficiência da gestão.

Nesse gerenciamento, os resíduos de natureza diferentes ficavam amontoados em determinadas áreas da empresa até atingir um volume suficiente para que pudessem ser retirados, classificados e destinados 
pela Central de Tratamento de Resíduos (CTR). Essa central localiza-se dentro do complexo e é gerida por uma empresa terceirizada para armazenar e controlar a destinação dos materiais. Contudo, o procedimento realizado era inadequado, pois armazenar os produtos conjuntamente podia provocar contaminação de um resíduo pelo outro, levando à perda de valor e reduzindo as possibilidades de reciclagem.

$\mathrm{Na}$ maioria das vezes, esse aprovisionamento inviabilizava as formas de tratamento adequadas e aumentava os gastos com aterros sanitários, uma vez que os resíduos contaminados não tinham outra opção de destinação. Isso acontecia com os papéis e papelões, que, no geral, podiam ser vendidos para empresas recicladoras, mas, quando contaminados por óleo lubrificante, acabavam tendo como destino final a disposição em aterros.

Então, a gestão de resíduos resumia-se em separar os resíduos contaminados dos não contaminados após a armazenagem e registrar os valores relacionados às receitas e às despesas com sua destinação. Os contaminados, que eram a maioria, iam para os aterros. Aqueles que não estavam contaminados eram vendidos para empresas recicladoras. Esse tipo de gerenciamento fazia com que as despesas com a classificação e destinação de resíduos fossem maiores do que as receitas obtidas.

\section{O gerenciamento de resíduos sólidos pós plano de gerenciamento de resíduos sólidos}

A partir do ano de 2015, o foco do gerenciamento de resíduos foi ampliado, passando a incorporar também a preocupação com algum tipo de ganho financeiro, seja na minimização de custos, seja no aumento de receitas. Por isso, foi desenvolvido um PGRS.
O diagnóstico inicial foi concebido a partir da análise dos fluxogramas de processos industriais e administrativos, identificando os resíduos produzidos, bem como suas principais áreas geradoras. Com esse desenho, os resíduos passaram a ser classificados em cada área geradora, obedecendo às normas da NBR 10004 (ABNT, 2014). São, ao todo, 15 tipos de resíduos sólidos classe I (grupo 1) e 48 tipos de classe II (grupo 2), que, atualmente, são gerenciados pelo PGRS e diferenciados em função de volume, qualidade e de acordo com a atividade geradora, conforme demonstrado nas Tabelas 1 e 2 .

A partir da identificação dos resíduos dentro da área geradora, o novo PGRS foi criado levando em consideração todo o ciclo de produção da empresa, a fim de monitorar os resíduos de forma sistêmica. Para isso, a área geradora foi designada para ser responsável pelo resíduo desde a sua produção até o seu destino final, a fim de que seja garantida a gestão de resíduos de forma ambientalmente correta, com qualidade e custos otimizados.

Para a concretização do PGRS, foi essencial que a usina e a empresa terceirizada estivessem integradas para apoiar o processo de gestão. Então, a primeira passou a se responsabilizar por segregar os resíduos, acondicioná-los e rotulá-los, além de pelas atividades de registro de acompanhamento e de documentos; e a segunda encarregou-se da retirada, do controle e do pagamento, mediante acordos, além de dar uma destinação mais apropriada aos resíduos. O fluxograma, representado por meio da Figura 1, mostra todas as etapas do manejo de resíduos na usina, inclusive o controle informatizado e a documentação de registro gerado.

Tabela 1 - Volume médio mensal de resíduos classe I gerados no complexo siderúrgico estudado.

\begin{tabular}{|c|c|c|c|c|c|}
\hline $\mathrm{N}^{\circ}$ & Resíduo & Área geradora & Classe & $\begin{array}{c}\text { Volume médio } \\
\text { mensal }\end{array}$ & $\%$ \\
\hline 1 & Embalagens plásticas contaminadas & Áreas industriais & I - Perigoso & 227,1 & 0,70 \\
\hline 3 & Óleo usado ou contaminado & Áreas industriais & I - Perigoso & 122,9 & 0,38 \\
\hline 4 & Pilhas e baterias usadas & Áreas industriais e áreas comuns & I - Perigoso & 29,2 & 0,09 \\
\hline 6 & Resíduo de caixa de esgoto & Áreas industriais & I - Perigoso & $1.802,1$ & 5,58 \\
\hline 7 & Resíduo de EPI & Áreas industriais & I - Perigoso & 81,3 & 0,25 \\
\hline 8 & Resíduo de produto químico & Áreas industriais & I - Perigoso & 2,8 & 0,01 \\
\hline 9 & Resíduo líquido contaminado & Áreas industriais & I - Perigoso & 336,3 & 1,04 \\
\hline 13 & Resíduo sólido de cromo & Areas industriais & I - Perigoso & 96,7 & 0,30 \\
\hline 14 & Resíduo sólido oleoso & Áreas industriais & I - Perigoso & 326,2 & 1,01 \\
\hline 15 & Sucata de bateria de chumbo ácida & Áreas industriais & I - Perigoso & 55,1 & 0,17 \\
\hline \multicolumn{4}{|l|}{ Total } & $32.280,0$ & 100 \\
\hline
\end{tabular}

EPI: equipamentos de proteção individual; ETE: estação de tratamento de efluentes. 
Tabela 2 - Volume médio mensal de resíduos classe Il de maior volume gerado no complexo siderúrgico estudado.

\begin{tabular}{|c|c|c|c|c|c|}
\hline No & Resíduo & Área geradora & Classe & $\begin{array}{l}\text { Volume médio } \\
\text { mensal }\end{array}$ & $\%$ \\
\hline 1 & Entulho da construção civil & Áreas industriais e comuns & II A - não inerte & $40.174,6$ & 3,09 \\
\hline 2 & Entulho do distribuidor & Aciaria & II B - inerte & $65.395,4$ & 5,04 \\
\hline 3 & Escória bruta de alto-forno & Alto-forno & II A - não inerte & $209.549,2$ & 16,14 \\
\hline 4 & Escória granulada de alto-forno & Alto-forno & II A - não inerte & 191.180,0 & 14,73 \\
\hline 5 & Escória primária de aciaria & Aciaria & II B - inerte & $100.487,1$ & 7,74 \\
\hline 6 & Escória secundária de aciaria & Aciaria & II A - não inerte & $132.611,3$ & 10,21 \\
\hline 7 & Finos de coque & Upstream & II A - não inerte & $8.312,1$ & 0,64 \\
\hline 8 & Finos de minério & Upstream & ॥ A - não inerte & 138,8 & 0,01 \\
\hline 9 & Lama de alto-forno & Estação de tratamento de efluentes & II B - inerte & 925,0 & 0,07 \\
\hline 10 & Lama de fosfatização & Downstream & II B - inerte & $1.502,5$ & 0,12 \\
\hline 11 & Lama do adensador & Estação de tratamento de água e efluentes & II A - não inerte & 283,3 & 0,02 \\
\hline 12 & Lama da estação de tratamento de água & Estação de tratamento de água e efluentes & II A - não inerte & $15.843,8$ & 1,22 \\
\hline 13 & Moinha de carvão vegetal & Áreas industriais & II A - não inerte & $225.100,0$ & 17,34 \\
\hline 14 & Pó do coletor & Alto-forno & ॥ A - não inerte & $117.318,3$ & 9,04 \\
\hline 15 & Pó de despoeiramento - aciaria/câmara & Aciaria & ॥ A - não inerte & $19.310,0$ & 1,49 \\
\hline 16 & Pó de despoeiramento - aciaria/ silo & Aciaria & II A - não inerte & 43.328,3 & 3,34 \\
\hline 17 & Pó de despoeiramento - carvão vegetal & Alto-forno & II B - inerte & $57.665,0$ & 4,44 \\
\hline 18 & Tiço de carvão vegetal & Alto-forno & II A - não inerte & $22.382,9$ & 1,72 \\
\hline 19 & Bobina de madeira & Áreas industriais & II A - não inerte & 37,5 & 0,00 \\
\hline 20 & Capas, cabos elétricos e alumínio & Áreas industriais & II B - inerte & 58,3 & 0,00 \\
\hline 21 & Carepa & Laminação e lingotamento contínuo & II A - não inerte & $5.685,4$ & 0,44 \\
\hline 22 & Discos abrasivos & Areas industriais & II A - não inerte & 24,6 & 0,00 \\
\hline 23 & Lixas usadas & Areas industriais & II A - não inerte & 27,8 & 0,00 \\
\hline 24 & Madeiras diversas & Áreas industriais e comuns & II A - não inerte & $2.188,8$ & 0,17 \\
\hline 25 & Pallets de madeira & Areas industriais & II A - não inerte & 102,9 & 0,01 \\
\hline 26 & Plástico, papéis e outros recicláveis & Áreas industriais e comuns & ॥ A - não inerte & 416,3 & 0,03 \\
\hline 27 & Rejeito comum (lixo comum) & Áreas comuns & ॥ A - não inerte & 5,0 & 0,00 \\
\hline 28 & Rejeito industrial & Areas industriais & ॥ A - não inerte & $2.932,1$ & 0,23 \\
\hline 29 & Resíduo de biomassa & Areas industriais & II A - não inerte & $1.204,2$ & 0,09 \\
\hline 30 & Resíduo de caixa de gordura & Cozinha industrial e refeitórios & II A - não inerte & $4.971,7$ & 0,38 \\
\hline 31 & Resíduo de embalagens plásticas & Áreas industriais & II B - inerte & 867,5 & 0,07 \\
\hline 32 & Resíduo de limpeza de baia/sucata & Aciaria & II A - não inerte & $6.463,3$ & 0,50 \\
\hline 33 & Resíduo de metal duro & Areas industriais & II B - inerte & 48,0 & 0,00 \\
\hline 34 & Resíduo de óleo vegetal & Cozinha industrial & ॥ A - não inerte & 424,0 & 0,03 \\
\hline 35 & Resíduo de vidro & Áreas industriais & II B - inerte & 156,7 & 0,01 \\
\hline 36 & Resíduo de ingestão & Cozinha industrial e refeitórios & II A - não inerte & $12.790,4$ & 0,99 \\
\hline 37 & Sucata de borracha & Areas industriais & II A - não inerte & 153,8 & 0,01 \\
\hline 38 & Sucata de cobre & Areas industriais & II B - inerte & 577,5 & 0,04 \\
\hline 39 & Sucata de correia transportadora & Areas industriais & ॥ A - não inerte & 60,0 & 0,00 \\
\hline 40 & Sucata de embalagem plástica & Areas industriais & II B - inerte & 123,3 & 0,01 \\
\hline 41 & Sucata de gusa & Areas industriais & II B - inerte & $3.476,3$ & 0,27 \\
\hline 42 & Sucata de limalha & Áreas industriais & II A - não inerte & $1.192,1$ & 0,09 \\
\hline 43 & Sucata de material refratário ácido & Areas industriais & II B - inerte & 634,6 & 0,05 \\
\hline 44 & Sucata de material refratário base & Areas industriais & II B - inerte & $1.030,0$ & 0,08 \\
\hline 45 & Sucata de material eletroeletrônico & Áreas industriais e comuns & II A - não inerte & 15,5 & 0,00 \\
\hline 46 & Sucata de embalagens metálicas & Areas industriais & Il A - não inerte & 6,2 & 0,00 \\
\hline 47 & Sucata de material refratário sílico & Areas industriais & II B - inerte & 898,3 & 0,07 \\
\hline 48 & Sucata metálica & Áreas industriais & ॥ A - não inerte & 180,8 & 0,01 \\
\hline \multicolumn{4}{|l|}{ Total } & $1.298 .260,0$ & 100 \\
\hline
\end{tabular}




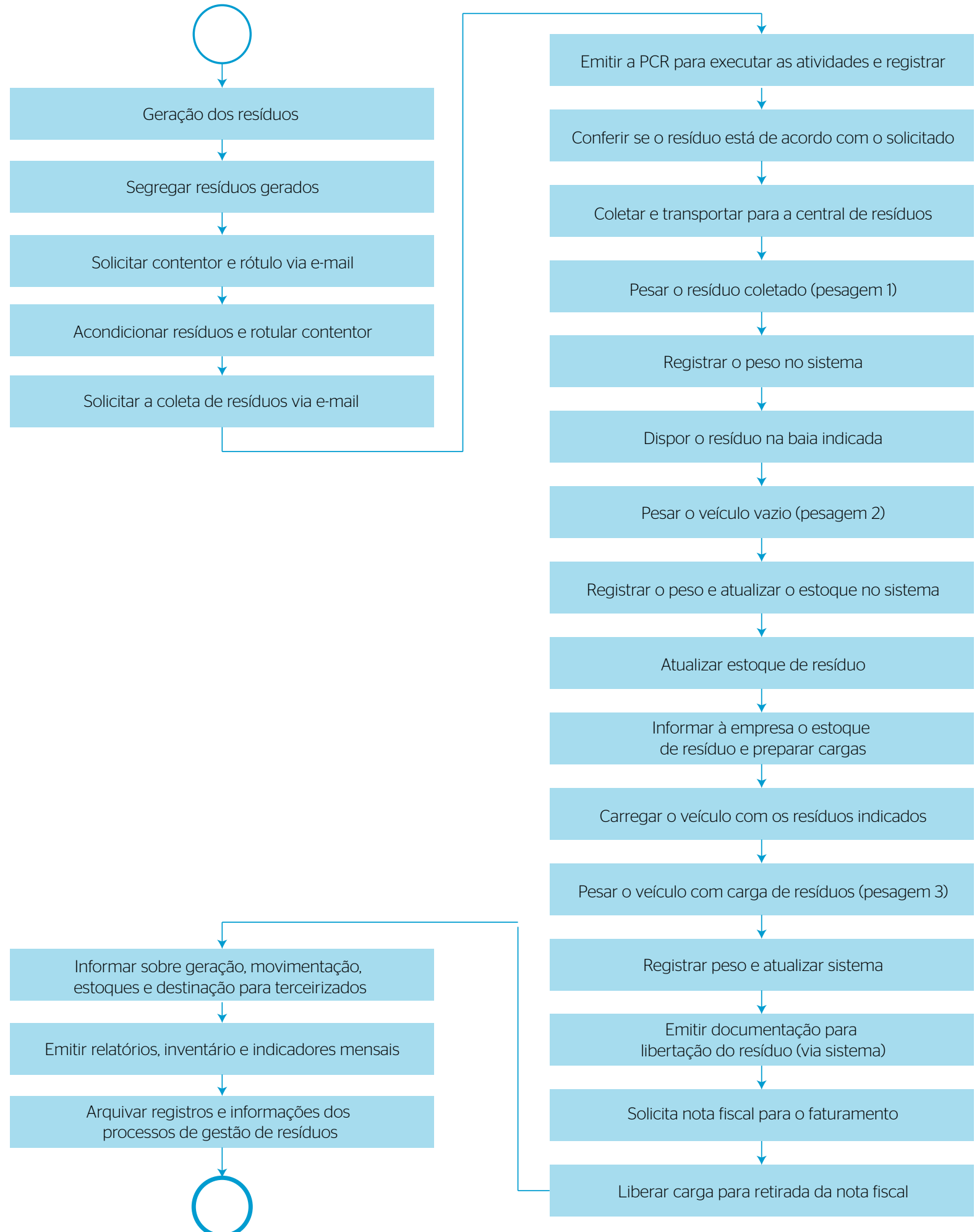

PCR: programação de controle de resíduos.

Figura 1 - Etapas do manejo de resíduos na usina, dentro do plano de gerenciamento de resíduos sólidos. 


\section{Segregação dos resíduos nas áreas da empresa: responsabilidade da usina}

Antes do PGRS, um dos grandes problemas enfrentados pela usina era a contaminação de um resíduo pelo outro, em virtude de serem alocados em um mesmo recipiente. Com o novo plano, foi realizada a segregação dos resíduos em todas as áreas, o que evita que resíduos acabem se misturando. A combinação de um resíduo com outro pode encarecer ou até inviabilizar a possibilidade de reutilização, reciclagem ou tratamento.

Sendo assim, os resíduos passaram a ser armazenados em embalagens e contentores fornecidos pela empresa terceirizada. Esses contentores variam de acordo com o tipo de material e, por isso, são usadas caixas apropriadas para lâmpadas, coletores para pilhas e baterias, bombonas, tambores, caçambas, big bags, lixeiras, baias de concreto, tanques coletores e contêineres e gaiolas coloridas (200 gaiolas).

No caso dessas últimas, utilizou-se a segregação dos resíduos conforme padrão do Conselho Nacional do Meio Ambiente (CONAMA), que atende aos padrões de segregação amplamente conhecidos. Assim, cada cor de gaiola representa um tipo de resíduo: azul para papel/papelão, vermelho para plástico, verde para vidro, branco para ambulatoriais e cinza para rejeito comum.

A fim de facilitar a identificação dos resíduos, também foi afixado nos contentores e nas embalagens um rótulo de identificação de fácil visualização, indelével, com símbolos e informações necessárias ao reconhecimento do conteúdo e dos riscos específicos. Essa identificação buscou orientar a segregação adequada nos locais de geração e facilitar o manuseio nas etapas seguintes. A segregação e a identificação ocorrem na usina. Segundo Carneiro (2013), identificar os resíduos permite o conhecimento de produtos gerados e ajuda a delinear as ações operacionais para redução do volume produzido.

\section{Coleta e transporte interno: responsabilidade da usina}

A movimentação interna dos resíduos passou a ser feita conforme rotina ou demandas das áreas geradoras. Os resíduos são coletados e transportados até os pontos intermediários de coleta (PIC), de acordo com as prioridades definidas e em função dos potenciais riscos, rotinas operacionais e quantidades dispostas. Geralmente, os resíduos do grupo 1, de classificação tipo I, por conta de seu grau de contaminação e perigo, possuem prioridades, em termos de urgência, de transporte interno até os PIC. Os pertencentes ao grupo 2 acabam ficando mais tempo próximos aos processos produtivos, principalmente os que apresentam grandes volumes, retirados no momento da venda ou do reúso no processo produtivo, como é o caso de escórias, lamas, finos e pós de despoeiramento. No geral, os resíduos são armazenados e enviados aos PIC.

Nos PIC, quando o volume chega perto da capacidade de armazenamento, é demandado para a terceirizada que seja feito o transporte até a CTR, onde os resíduos ficarão estocados até sua destinação final. Para garantir a integridade do produto, antes da coleta, a empresa terceirizada realiza inspeção das embalagens quanto à segregação, ao acondicionamento e à identificação dos resíduos. No trabalho de Sanches, Mendonça e Feichas (2013), os resultados demonstraram a contaminação de resíduos durante o armazenamento e transporte, tornando clara a importância da segregação dos resíduos em sua geração.

\section{Armazenamento temporário de resíduos: responsabilidade da terceirizada}

Nessa etapa, os resíduos ficam estocados em uma CTR até formarem um lote econômico que otimize o transporte e justifique a sua expedição para a destinação final. No galpão de resíduos, são feitos o condicionamento e o acondicionamento de resíduos, tais como: plásticos, papéis, papelão, tambores metálicos etc. Nesse armazenamento interno, há entrepostos exclusivos para resíduos perigosos e não perigosos, de acordo com as exigências dos órgãos de controle, como a Fundação Estadual do Meio Ambiente (FEAM) e o Instituto Brasileiro do Meio Ambiente e dos Recursos Naturais Renováveis (IBAMA).

\section{Expedição dos resíduos: responsabilidade da terceirizada}

$\mathrm{Na}$ expedição dos resíduos, ocorrem as seguintes atividades: inspeção do veículo, tara, carregamento, lavagem dos pneus, pesagem final, enlonamento e emissão da documentação para liberação da viagem até o destino final. Essas atividades são realizadas pela terceirizada sob a responsabilidade de um setor do complexo siderúrgico. Os veículos de transporte devem ser inspecionados, antes do carregamento, para garantir que estarão com toda a documentação obrigatória e com os itens de segurança conforme a legislação pertinente. Após a preparação da carga, é feita uma nova inspeção para garantir a conformidade de todos os itens necessários. Em seguida, a carga é pesada, enlonada e liberada para seguir viagem.

\section{Transporte externo de resíduos: responsabilidade da terceirizada}

O transporte externo de resíduos é de responsabilidade da empresa terceirizada, que deve contratar as transportadoras, exigindo o atendimento aos itens de segurança e requisitos legais pertinentes à carga que transportarão. Essa empresa realiza todos os preparativos necessários ao transporte externo, na etapa de expedição, providenciando documentação necessária, pesagem da carga e seu registro.

\section{Destinação final de resíduos: responsabilidade da terceirizada}

No novo plano, quem decide a destinação final dos resíduos é a empresa terceirizada. Nesse processo, é obedecida uma hierarquia de prioridades 
para tratamento de resíduos, baseada nos modelos de gerenciamento de resíduos da Europa (WOLSINK, 2010) e dos Estados Unidos (FRANCHETTI, 2009) e adaptada para a realidade do complexo. Tal modelo busca minimizar os impactos ambientais relacionados ao não tratamento ou à disposição inadequada por meio de cinco opções:

- comercialização;

- reutilização do resíduo;

- reciclagem;

- recuperação do resíduo;

- disposição (Figura 2).

A decisão pela opção de gerenciamento leva em consideração as características, o grau de periculosidade, a toxidade e o potencial poluidor dos resíduos (Quadro 1). A comercialização é usada para subprodutos ou coprodutos como a escória, que é vendida na medida em que é produzida. A reutilização é usada para bobinas de madeira, lama de alto forno, pallets e outros, no sentido de retroalimentá-los na sua própria cadeia produtiva ou em outra, por meio do reúso interno. A reciclagem é usada para embalagens plásticas e de vidro, papéis, papelões, óleos vegetais e outros, com o propósito de transformá-los novamente em produtos ou materiais, por meio do reprocessamento ou beneficiamento. A recuperação é usada para os resíduos de equipamentos de proteção individual (EPI), os oleosos e os relacionados com a construção civil e, no geral, consiste em outros tipos de valorização de resíduos, sendo o reaproveitamento energético a forma mais usada. A disposição é usada após esgotadas as possibilidades de tratamento e está relacionada com as incinerações usadas para os resíduos de saúde e a disposição em aterros sanitários para resíduos contaminados, após tratamento de redução dos riscos inerentes (inertização).

De acordo com Angelo (2014), a hierarquia dos resíduos, do ponto de vista da sustentabilidade, reduz ao máximo a disposição de resíduos em aterros sanitários, de modo que estes recebam apenas os rejeitos,

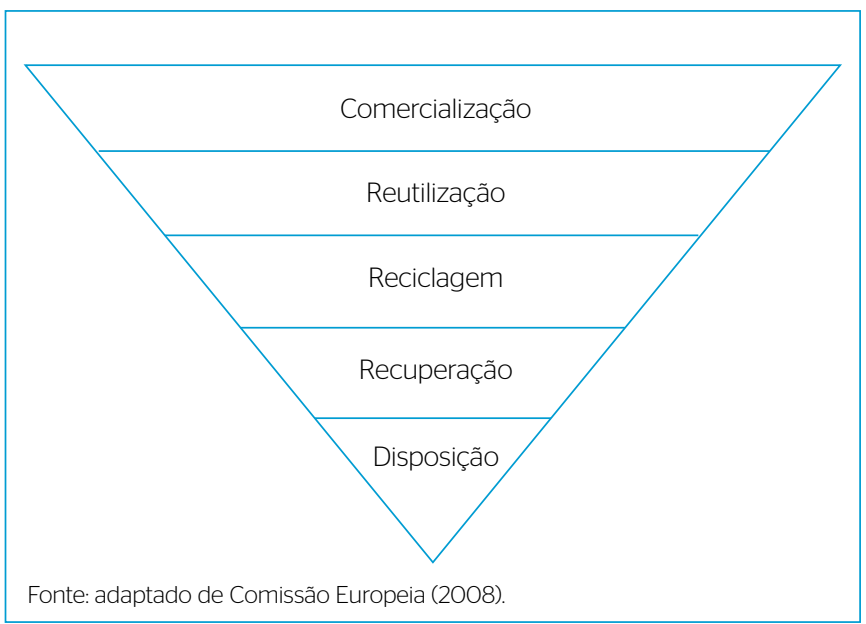

Figura 2 - Hierarquia dos resíduos adotada pelo complexo siderúrgico. garantindo que as futuras gerações não sofram os danos ambientais causados pela disposição dos resíduos produzidos pelas anteriores. No entanto, a autora chama atenção para que, muitas vezes, seguir apenas a hierarquia dos resíduos pode levar a decisões arbitrárias em relação à escolha da melhor opção de destinação dos resíduos do ponto de vista ambiental. Por isso, ela deve ser acompanhada da ferramenta de suporte denominada de análise do ciclo de vida.

Além da hierarquia de prioridades, leva-se em consideração o atendimento aos seguintes aspectos na contratação dos receptores finais: localização e capacidade de gestão de resíduos do receptor; tipo de gestão adotada pelo receptor; tecnologia seguida; condições das instalações; impactos ambientais gerados pelo processamento dos resíduos; medidas mitigadoras; licenciamento ambiental do receptor para o processamento; capacitação técnica do pessoal; condições de saúde e segurança ocupacionais; capacidade de debelar emergências ambientais; necessidade de tratamento dos resíduos antes de serem enviados para o seu destino final; alternativas comerciais; e atendimento à legislação e normas aplicáveis.

\section{Impactos ambientais e financeiros com a implantação do plano de gerenciamento de resíduos sólidos}

No aspecto ambiental, as mudanças e os benefícios com o PGRS dizem respeito à qualidade e à quantidade de material (Tabelas 1 e 2) encaminhado para comercialização, reutilização, reciclagem, recuperação/ coprocessamento (processo de destruição térmica de resíduos em fornos industriais de cimenteiras, coproduto) e destinação final ambientalmente adequada.

No aspecto financeiro, o novo PGRS permitiu a venda de coprodutos e de materiais para reciclagem, a redução de custos de tratamento e de materiais contaminados aos aterros sanitários e o reúso de materiais não virgens. O impacto dessas ações pode ser verificado nos registros de receitas e despesas nos anos de 2014 e 2015. Assim, os resultados corroboram as ideias de autores como Santin (2009), Hwang e Yeo (2011), Yuan (2012), Yates (2013) e Arnosti Jr. e Trinca (2015), os quais apresentaram as inúmeras vantagens econômicas trazidas pela reciclagem de construção civil; Paschoalin Filho et al. (2015), que comprovaram economia de até $64 \%$ no custo na construção civil, usando resíduos reciclados; Carneiro (2013), que mostrou a redução de custos trazida por meio da adoção do plano de resíduos em um restaurante institucional; e Sanches, Mendonça e Feichas (2013), que mostraram possíveis ganhos financeiros no processo de manutenção da área de pintura, por meio de estratégias de segregação e controle adequados de resíduos, com vendas de resíduos e reduções de custos, principalmente, relacionado à disposição final.

No ano de 2014 (Tabela 3), as receitas obtidas (R\$ 1.592.393,47) foram inferiores às despesas $(\mathrm{R} \$ 2.050 .912,15)$ com o gerenciamento de resíduos, indicando uma perda de valor e um aproveitamento inadequado dos resíduos ao longo do ano. Isso fez com que o resultado do gerenciamento de resíduos fosse negativo em - $\mathrm{R} \$ 458.518,68$ 
( $R \$ 1.592 .393,47-R \$ 2.050 .912,15)$, representando um resultado de $\mathrm{R} \$ 2,75$ por tonelada de aço produzida no ano (- $\mathrm{R} \$ 458.518,68 / 166.979 \mathrm{t})$. Até então, o gerenciamento preocupava-se mais em atender a legislações sanitárias e ambientais, as quais, segundo o raciocínio de Sanches, Mendonça e Feichas (2013) e Angelo (2014), são vistas mais como custos do que como possibilidades de ganhos.

Quadro 1 - Tratamento destinado a cada resíduo dos grupos 1 e 2.

\begin{tabular}{|c|c|c|c|c|c|}
\hline No & Resíduo & Tratamento & $\mathrm{N}^{\circ}$ & Resíduo & Tratamento \\
\hline \multicolumn{6}{|c|}{ Grupo 1} \\
\hline 1 & $\begin{array}{l}\text { Embalagens plásticas } \\
\text { contaminadas }\end{array}$ & Outras (transferência) & 9 & Resíduo líquido contaminado & Tratamento físico-químico \\
\hline 2 & Lâmpadas para descarte & Reciclagem & 10 & Resíduo líquido de cromo & Tratamento físico-químico \\
\hline 3 & Óleo usado ou contaminado & Reciclagem & 11 & Resíduo líquido oleoso & Tratamento físico-químico \\
\hline 4 & Pilhas e baterias usadas & Outras (transferência) & 12 & Resíduo de serviço de saúde & Incineração \\
\hline 5 & Resíduo biológico & Outras (compostagem) & 13 & Resíduo sólido de cromo & Coprocessamento \\
\hline 6 & Resíduo de caixa de esgoto & Tratamento biológico & 14 & Resíduo sólido oleoso & Coprocessamento \\
\hline 7 & $\begin{array}{l}\text { Resíduo de equipamento } \\
\text { de proteção individual }\end{array}$ & Coprocessamento & 15 & Sucata de bateria de chumbo ácida & Reciclagem \\
\hline 8 & Resíduo de produto químico & Estocagem temporária & & & \\
\hline \multicolumn{6}{|c|}{ Grupo 2} \\
\hline 1 & Entulho da construção civil & Aplicação no solo & 25 & Pallets de madeira & Reutilização \\
\hline 2 & Entulho do distribuidor & Reciclagem & 26 & Plástico, papéis e outros recicláveis & Reciclagem \\
\hline 3 & Escória bruta de alto-forno & Reciclagem & 27 & Rejeito comum (lixo comum) & Aterro industrial \\
\hline 4 & Escória granulada de alto-forno & Outras (beneficiamento) & 28 & Rejeito industrial & Aterro industrial \\
\hline 5 & Escória primária de aciaria & Reciclagem & 29 & Resíduo de biomassa & Destinação interna \\
\hline 6 & Escória secundária de aciaria & Reciclagem & 30 & Resíduo de caixa de gordura & Tratamento biológico \\
\hline 7 & Finos de coque & Reciclagem & 31 & Resíduo de embalagens plásticas & Reciclagem \\
\hline 8 & Finos de minério & Outras (beneficiamento) & 32 & Resíduo de limpeza de baia/sucata & Reciclagem \\
\hline 9 & Lama de alto-forno & Outras (transferência) & 33 & Resíduo de metal duro & Estocagem temporária \\
\hline 10 & Lama de fosfatização & Reciclagem & 34 & Resíduo de óleo vegetal & Reciclagem \\
\hline 11 & Lama do adensador & Reciclagem & 35 & Resíduo de vidro & Reciclagem \\
\hline 12 & $\begin{array}{l}\text { Lama da estação de } \\
\text { tratamento de água }\end{array}$ & Aterro industrial & 36 & Resíduo de ingestão & Compostagem \\
\hline 13 & Moinha de carvão vegetal & Reciclagem & 37 & Sucata de borracha & Outras (transferência) \\
\hline 14 & Pó do coletor & $\begin{array}{c}\text { Outras (aproveiramento) } \\
\text { energético) }\end{array}$ & 38 & Sucata de cobre & Outras (transferência) \\
\hline 15 & $\begin{array}{c}\text { Pó de despoeiramento - } \\
\text { aciaria/câmara }\end{array}$ & Aplicação no solo & 39 & Sucata de correia transportadora & Reutilização \\
\hline 16 & $\begin{array}{c}\text { Pó de despoeiramento - } \\
\text { aciaria/silo }\end{array}$ & Reciclagem & 40 & Sucata de embalagem plástica & Outras (transferência) \\
\hline 17 & $\begin{array}{l}\text { Pó de despoeiramento - } \\
\text { carvão vegetal }\end{array}$ & Reciclagem & 41 & Sucata de gusa & Reciclagem \\
\hline 18 & Tiço de carvão vegetal & Outras (beneficiamento) & 42 & Sucata de limalha & Estocagem temporária \\
\hline 19 & Bobina de madeira & Reutilização & 43 & Sucata de material refratário ácido & Reciclagem \\
\hline 20 & Capas, cabos elétricos e alumínio & Reciclagem & 44 & Sucata de material refratário base & Reciclagem \\
\hline 21 & Carepa & Reciclagem & 45 & Sucata de material eletroeletrônico & Outras (beneficiamento) \\
\hline 22 & Discos abrasivos & Outras (transferência) & 46 & Sucata de embalagens metálicas & Reciclagem \\
\hline 23 & Lixas usadas & Estocagem temporária & 47 & Sucata de material refratário sílico & Reciclagem \\
\hline 24 & Madeiras diversas & $\begin{array}{c}\text { Outras (aproveiramento) } \\
\text { energético) }\end{array}$ & 48 & Sucata metálica & Outras (transferência) \\
\hline
\end{tabular}


No ano de 2015 (Tabela 4), após a implantação do PGRS, as receitas com o gerenciamento de resíduos $(\mathrm{R} \$ 2.191 .543,09)$ superaram as despesas (R\$1.651.189,51), mostrando um ganho financeiro anual de $\mathrm{R} \$ 540.353,59$ ( $\mathrm{R} \$ 2.191 .543,09-\mathrm{R} \$ 1.651 .189,51)$, equivalente a lucro de $\mathrm{R} \$ 3,92(\mathrm{R} \$ 540.353,59 / 137.947 \mathrm{t})$ por tonelada. Segundo Coelho et al. (2011), a diferença dos elementos receitas, despesas e resultado pode ser analisada por meio dos indicadores de acompanhamento de desempenho do gerenciamento de resíduos, tais como: receita.t aço-1, despesas.t aço ${ }^{-1}$ e resultado.t aço-1. Esses indicadores mostram a evolução ao longo do primeiro semestre nos dois anos, registrando duas realidades: a primeira, em que há grandes gastos sem retorno compatível, e a segunda, apresentando indicadores positivos e em expansão.

Então, a adoção do novo PGRS no complexo siderúrgico mostrou queé possível, por meio de um trabalho coletivo e focado, desenvolver e implantar um sistema eficiente de gestão de resíduos. Além disso, por considerar processos para reutilizações interna e externa de resíduos, o plano trouxe possibilidades de ganhos para o meio ambiente na redução de perdas de matéria-prima e insumos e de ganhos financeiros sem, portanto, exigir grandes investimentos em estrutura, equipamentos e serviços de consultoria.

\section{CONCLUSÕES}

Este trabalho teve como finalidade analisar o processo de implantação do PGRS em um complexo siderúrgico, de modo que se identificassem possíveis ganhos financeiros associados aos ambientais. Para isso, foi utilizada uma pesquisa qualitativa de cunhos descritivo e analítico.
O complexo siderúrgico optou pela implantação de um PGRS com foco em economia e lucratividade e ainda sem grandes investimentos, reestruturando o gerenciamento de resíduos e analisando o processo de maneira sistêmica. Dessa maneira, o plano definiu a área geradora como responsável pelo resíduo, de modo que se garanta a gestão de forma ambientalmente correta, com qualidade e custos otimizados.

Nessa gestão, a destinação final obedece a uma hierarquia de prioridades para tratamento de resíduos por meio de cinco opções de gerenciamento: comercialização, reutilização do resíduo, reciclagem, recuperação do resíduo e eliminação (incineração e disposição em aterro sanitário). Cada opção leva em consideração as características, o grau de periculosidade, a toxidade e o potencial poluidor dos resíduos.

A hierarquia dos resíduos, do ponto de vista da sustentabilidade, reduz ao máximo a disposição de resíduos em aterros sanitários, de modo que estes recebam apenas os rejeitos, garantindo que as futuras gerações não sofram os danos ambientais causados pela disposição dos resíduos produzidos pelas gerações anteriores.

Além de o PGRS atender às normas ambientais vigentes nos âmbitos federal, estadual e municipal, por considerar processos para reutilizações interna e externa de resíduos, ele ainda traz possibilidades de ganhos para o meio ambiente com a redução de perdas de matéria-prima e insumos e aumento de ganhos financeiros.

A análise de indicadores mostrou que, até o ano de 2014, as despesas com o gerenciamento de resíduos eram maiores que as receitas. Já em 2015, com a implantação do PGRS, houve aumento de receitas, provenientes de venda de resíduos recicláveis e redução de custos de

Tabela 3 - Indicadores de desempenho financeiro do gerenciamento de resíduos adotado no ano de 2014.

\begin{tabular}{|c|c|c|c|c|c|c|c|}
\hline Indicador & Janeiro & Fevereiro & Março & Abril & Maio & Junho & Total \\
\hline Toneladas produzidas de aço & 24.330 & 26.805 & 25.669 & 32.179 & 24.378 & 33.617 & 166.979 \\
\hline Receita com resíduos ( $R \$$ ) & $287.514,61$ & 256.429,92 & $232.517,20$ & $320.244,53$ & $258.858,39$ & $236.828,82$ & $1.592 .393,47$ \\
\hline Despesas com resíduos ( $R \$$ ) & $296.622,44$ & $260.530,29$ & $333.515,23$ & $387.379,51$ & 465.375,99 & $307.488,67$ & 2.050.912,15 \\
\hline Resultado (R\$) & - 9.107,83 & - 4.100,37 & - 100.998,03 & - 67.134,99 & - 206.517,61 & - 70.659,85 & - 458.518,68 \\
\hline Receita.t aço-1 & 11,82 & 9,57 & 9,06 & 9,95 & 10,62 & 7,04 & 9,54 \\
\hline Despesas.t aço-1 & 12,19 & 9,72 & 12,99 & 12,04 & 19,09 & 9,15 & 12,28 \\
\hline Resultado.t aço-1 & $-0,37$ & - 0,15 & $-3,93$ & $-2,09$ & $-8,47$ & $-2,10$ & $-2,75$ \\
\hline
\end{tabular}

Tabela 4 - Indicadores de desempenho financeiro do gerenciamento de resíduos adotado no ano de 2015.

\begin{tabular}{|c|c|c|c|c|c|c|c|}
\hline Indicador & Janeiro & Fevereiro & Março & Abril & Maio & Junho & Total \\
\hline Toneladas produzidas de aço & 23.813 & 30.638 & 23.437 & 18.599 & 27.992 & 13.467 & 137.947 \\
\hline Receita com resíduos ( $R \$$ ) & $321.050,79$ & $406.756,42$ & $334.577,56$ & 359.246,09 & $440.958,49$ & $328.953,74$ & 2.191.543,09 \\
\hline Despesas com resíduos (R\$) & $273.590,23$ & 301.188,39 & 291.227,61 & $246.473,28$ & $267.237,57$ & $271.472,43$ & $1.651 .189,51$ \\
\hline Resultado (R\$) & $47.460,56$ & $105.568,03$ & $43.349,95$ & $112.772,81$ & $173.720,92$ & $57.481,31$ & $540.353,59$ \\
\hline Receita.t aço-1 & 13,48 & 13,28 & 14,28 & 19,31 & 15,75 & 24,43 & 15,89 \\
\hline Despesas.t aço-1 & 11,49 & 9,83 & 12,43 & 13,25 & 9,55 & 20,16 & 11,97 \\
\hline Resultado.t aço-1 & 1,99 & 3,45 & 1,85 & 6,06 & 6,21 & 4,27 & 3,92 \\
\hline
\end{tabular}


tratamento de resíduos. Desse modo, mostrou-se que é possível, com um trabalho coletivo e focado, atender legislações ambientais, englobando os resíduos gerados em todo o processo e ainda trazer um retorno financeiro para a empresa.

Algumas limitações apontadas pelo estudo foram:

- por falta de acesso às informações, os indicadores financeiros foram levantados com base nos primeiros semestres dos anos de $2014 \mathrm{e}$ 2015, sendo necessária a continuidade da aplicação desses indicadores ao longo do tempo para avaliar o desempenho do PGRS;

- o estudo concentrou-se no fluxo do processo de segregação e tratamento de resíduo, não detalhando informações a respeito de novas tecnologias e novas técnicas mais apropriadas de gerenciamento de resíduos sólidos, que poderiam impactar na melhoria do processo;

- a escolha da melhor opção de gerenciamento de resíduos apenas com base na hierarquia dos resíduos pode levar a decisões arbitrárias do ponto de vista ambiental, devendo ser acompanhada da ferramenta denominada de análise do ciclo de vida, que não foi usada na tomada de decisão do caso estudado.

Tais limitações podem ser consideradas como sugestões para novas pesquisas.

\section{REFERÊNCIAS}

AGÊNCIA NACIONAL DE VIGILÂNCIA SANITÁRIA (ANVISA). (2OO3) Resolução RDC no2, de 8 de janeiro de 2003. Rio de Janeiro: ANVISA.

ANGELO, A.C.M. (2014) Contribuições para o inventário do ciclo de vida dos resíduos orgânicos provenientes da coleta domiciliar na cidade do Rio de Janeiro. Dissertação (Mestrado) - Instituto Alberto Luiz Coimbra de Pós-Graduação e Pesquisa de Engenharia, Universidade Federal do Rio de Janeiro, Rio de Janeiro.

ARNOSTI JR., S.; TRINCA, A.C. (2015) Implementation and performance evaluation of solid waste management plan comparison of multi-family construction works. Holos Environment, v. 15, p. 63-74. Disponível em: <https://www.cea-unesp.org.br/holos/ article/view/8885/6687>. Acesso em: 16 ago. 2016.

ASSOCIAÇÃO BRASILEIRA DE NORMAS TÉCNICAS (ABNT). (2004) NBR 10004: Classificação de Resíduos Sólidos. Rio de Janeiro: ABNT.

BARTHOLOMEU, D.B.; CAIXETA-FILHO, J.V. (orgs.). (2011) Logística ambiental de resíduos sólidos. São Paulo: Atlas. 264 p.

BRASIL. (2010a) Presidência da República. Decreto no 7.404, de 23 de dezembro de 2010. Disponível em: <http://www.planalto. gov.br/ccivil_O3/_Ato2007-2010/2010/Decreto/D7404.htm>. Acesso em: $1 \overline{6}$ ago. 2016.

(2010b) Presidência da República. Lei no 12.305, de 2 de agosto de 2010. Disponível em: <http://www.planalto.gov.br/ ccivil_O3/_ato2007-2010/2010/lei//12305.htm\#targetText=LEI\%2O N\%C2\%BA\%2O12.305\%2C\%2ODE\%2O2\%2ODE\%2OAGOSTO\%2O DE\%2O2010.\&targetText=Institui\%2Oa\%2OPol\%C3\%ADtica\%2O Nacional\%20de,1998\%3B\%20e\%20d\%C3\%A1\%20outras\%20 provid\%C3\%AAncias>. Acesso em: 16 ago. 2016

CARNEIRO, C.L. (2013) Plan for integrate management of solid residues in the institutional restaurant: operational tool targeting improvements in environmental management. Holos Environment, v. 13, n. 2 , p. $130-140$

CARVALHO, A.R. de; OLIVEIRA, M.V.C. (2003) Princípios básicos do saneamento do meio. São Paulo: Senac São Paulo. 400 p.
COELHO, H.M.G.; LANGE, L.C.; JESUS, L.F.L.; SARTORI, M.R. (2O11) Purpose of an Industrial Solid Waste Destination Index. Engenharia Sanitária e Ambiental, v. 16, n. 3, p. 307-316. http://dx.doi.org/10.1590/ S1413-41522011000300014

COMISSÃO EUROPEIA. (2008) Diretiva 2008/98/CE do Parlamento Europeu e do Conselho - relativa aos resíduos e que revoga certas diretivas. União Europeia: Comissão Europeia.

DEMO, P. (2012) Pesquisa e Informação Qualitativa. 5. ed. Campinas: Papirus. 135 p.

FERREIRA, V.A.; TAMBOURGI, E.B. (2009) A importância do gerenciamento de resíduos sólidos urbanos. Exacta, v. 7, n. 2, p. 157-163. https://doi.org/10.5585/exacta.v7i2.1633

FRANCHETTI, M.J. (2009) Solid waste analysis and minimization: a systems approach. Nova York: McGraw-Hill.

HWANG, B.G.; YEO, Z.B. (2011) Perception on benefits of construction waste management in the Singapore construction industry. Engineering, Construction and Architectural Management, v. 18, n. 4, p. 394-406. https://doi. org/10.1108/09699981111145835

MACHADO, H.H.; SGORLON, J.G.; ALTOÉ, S.P.S.; MENEGUETTI, K.S.; OLIVEIRA, J.C.D.; MARTINS, C.H.; TAVARES, C.R.G. (2012) A gestão dos resíduos sólidos industriais aplicada em países desenvolvidos e em desenvolvimento. In: CONGRESO LATINOAMERICANO DE ECOLOGÍA URBANA, 1., 2012, Buenos Aires. Anais... Disponível em: <https://www.researchgate.net/publication/262003297_A_ GESTAO_DOS_RESIDUOS_SOLIDOS_INDUSTRIAIS_APLICADA_A_ PAISES_DESENVOLVIDOS_E_EM_DESENVOLVIMENTO>. AcesSO em: 16 mar. 2016.

PASCHOALIN FILHO, J.A.; STOROPOLI, J.H.; DIAS, A.G.; DUARTE, E.B.L. (2015) Gerenciamento dos resíduos de demolição gerados nas obras de um edifício localizado na Zona Leste da Cidade de São Paulo/SP. Desenvolvimento em Questão, v. 13, n. 30, p. 265-305. https://doi.org/10.21527/22376453.2015.30.265-305 
PHILIP JR., A. (2005) Saneamento, saúde e ambiente: fundamentos para um desenvolvimento sustentável. Barueri: Manole. 842 p.

RAMPAZZO, L. (2015) Metodologia científica: para alunos dos cursos de graduação e pós-graduação. São Paulo: Loyola. 139 p.

RIBEIRO, D.V.; MORELLI, M.R. (2009) Resíduos sólidos: problema ou oportunidade? Rio de Janeiro: Interciência.

SANCHES, E.S.; MENDONÇA, F.M.; FEICHAS, S.A.Q. (2O13) Análise de processo de gerenciamento de resíduos do setor de manutenção da área de pintura de montadora de automóveis: estudo de caso. In: ENEGEP, 33., 2013, Salvador. Anais... Salvador.

SANTIN, O.G. (2009) Environmental assessment of construction trends in Mexico: towards sustainable building? Structural Survey, v. 27, n. 5, p. 361-371. http://dx.doi.org/10.1108/02630800911002620

TAM, V.W.Y.; SHEN, L.Y.; FUNG, I.W.H.; WANG, J.Y. (2007) Controlling construction waste by implementing governmental ordinances in Hong Kong. Construction Inovation, v. 7, n. 2, p. 149-166.

THIOLLENT, M. (2011) Metodologia da Pesquisa-ação. 18. ed. São Paulo: Cortez. 132 p.
TOCCHETTO, M.R.L. (2005) Gerenciamento de resíduos sólidos industriais. Química Industrial. Santa Maria: UFSM. Disponível em: <http://www.blogdocancado.com/wp-content/uploads/2012/04/ gerenciamento-de-residuos-solidos-industriais.pdf>. Acesso em: 9 mar. 2016.

TRIVIÑOS, A.N.S. (2009) Introdução à pesquisa em ciências sociais. São Paulo: Atlas. 175 p.

WOLSINK, M. (2010) Contested environmental policy infrastructure: Socio-political acceptance of renewable energy, water, and waste facilities. Environmental Impact Assessment Review, v. 30, n. 5 , p. 302-311. http://dx.doi.org/10.1016/j.eiar.2010.01.001

YATES, J.K. (2013) Sustainable methods for waste minimization in construction. Construction Innovation, v. 13, n. 3, p. 281-301. http:// dx.doi.org/10.1108/Cl-Nov-2011-0054

YIN, R.K. (2015) Estudo de Caso. Planejamento e Métodos. São Paulo: Bookman. 271 p.

YUAN, H. (2012) A model for evaluating the social performance of construction waste management. Waste Management, v. 32, n. 6 , p. 1218-1228. https://doi.org/10.1016/j.wasman.2012.01.028 